\title{
A viral epitope that mimics a self antigen can accelerate but not initiate autoimmune diabetes
}

\author{
Urs Christen, ${ }^{1}$ Kurt H. Edelmann, ${ }^{2}$ Dorian B. McGavern, ${ }^{2}$ Tom Wolfe, ${ }^{1}$ Bryan Coon, ${ }^{1}$ \\ Meghann K. Teague, ${ }^{3}$ Stephen D. Miller, ${ }^{3}$ Michael B.A. Oldstone, ${ }^{2}$ and Matthias G. von Herrath \\ ${ }^{1}$ Immune Regulation Lab, Department of Developmental Immunology, La Jolla Institute for Allergy and Immunology, San Diego, California, USA. \\ 2Division of Virology, Department of Neuropharmacology, The Scripps Research Institute, La Jolla, California, USA. ${ }^{3}$ Department of Microbiology-Immunology, \\ Northwestern University Medical School, Chicago, Illinois, USA.
}

\begin{abstract}
We document here that infection of prediabetic mice with a virus expressing an $\mathbf{H}-2 \mathrm{~K}^{\mathrm{b}}-$ restricted mimic ligand to a self epitope present on $\beta$ cells accelerates the development of autoimmune diabetes. Immunization with the mimic ligand expanded autoreactive $T$ cell populations, which was followed by their trafficking to the islets, as visualized in situ by tetramer staining. In contrast, the mimic ligand did not generate sufficient autoreactive $\mathrm{T}$ cells in naive mice to initiate disease. Diabetes acceleration did not occur in $\mathrm{H}-2 \mathrm{~K}^{\mathrm{b}}-$ deficient mice or in mice tolerized to the mimic ligand. Thus, arenavirus-expressed mimics of self antigens accelerate a previously established autoimmune process. Sequential heterologous viral infections might therefore act in concert to precipitate clinical autoimmune disease, even if single exposure to a viral mimic does not always cause sufficient tissue destruction.
\end{abstract}

\section{Introduction}

Evidence obtained by study of genetically identical twin pairs indicates that environmental or epigenetic factors play a role during the pathogenesis of human autoimmune diseases (1). Furthermore, epidemiological studies have associated infections with many different viruses with autoimmune diseases like type 1 diabetes (T1D) (2-5) and MS (6-9). However, it is still unclear how these infectious agents would cause autoimmunity. Molecular mimicry is one hypothesis to explain such a link mechanistically, and it postulates that cross-reactions with "foreign" (infectious) ligands during host defense activate autoreactive lymphocytes or, conversely, that lymphocytes activated during antiviral responses recognize autoantigens, thus initiating an autoimmune process. Evidence for this concept (reviewed in refs. $10,11)$ has involved the demonstration of T lymphocytes or antibodies cross-reactive with host proteins $(12,13)$. For example, $\mathrm{T}$ lymphocyte clones recovered from patients with MS recognized both viral epitopes as well as self (myelin) ligands (14). In human T1D, Honeyman and colleagues have found a significant link between the occurrence of rotavirus infections in young children and the emergence of islet antibodies, suggesting cross-reactivity between rotavirus and islet antigens (15). However, the association of T1D and rotavirus infections is still controversial, as a similar study from Finland (16) could not confirm the results obtained in the Australian series (15).

Nonstandard abbreviations used: EDCI, 1-ethyl-3-(3-dimethylaminopropyl)carbodiimide; GP, glycoprotein; HSK, herpes stromal keratitis; HSV-1, murine herpesvirus $1 ; \mathrm{K}^{\mathrm{b}}(-), \mathrm{H}-2 \mathrm{~K}^{\mathrm{b}}$-deficient; $\mathrm{K}^{\mathrm{b}}(+), \mathrm{H}-2 \mathrm{~K}^{\mathrm{b}}$-sufficient; LCMV, lymphocytic choriomeningitis virus; LCMV-Arm, LCMV strain Armstrong; LCMV-Arm-Var, LCMV-Arm escape variant; LCMV-Past, LCMV strain Pasteur; NGS, normal goat serum; NP, nucleoprotein; PDLN, pancreatic draining lymph node; poly(I:C), polyinosinic-polycytidylic acid; PV, Pichinde virus; RIP, rat insulin promoter; T1D, type 1 diabetes; TMEV, Theiler murine encephalomyelitis virus.

Conflict of interest: The authors have declared that no conflict of interest exists.

Citation for this article: J. Clin. Invest. 114:1290-1298 (2004).

doi:10.1172/JCI200422557.
Although molecular mimicry has been studied extensively as an initiating event for autoimmunity, little is known about its effect on an already established, ongoing autoimmune process. This was the focus of our study here. Murine animal models of autoimmunity have defined three separate mechanisms that may act alone or together in the causation of autoimmune disease: molecular mimicry (reviewed in refs. 17-20), epitope spreading $(19,21)$, and bystander activation (22-26). We focused here on molecular mimicry using a murine T1D model of heterologous, sequential viral infections. We elucidated a novel mechanistic link between infectious events and autoimmune disease by showing that mimicry between viral and self antigens can accelerate but not easily initiate autoimmune diabetes.

Heterologous virus infections have typically been considered positive enhancers of overall immune health through the repeated activation of cross-reactive memory T lymphocytes (27). Via this mechanism, immunity to one organism can provide an advantage to the host in combating new infections without severely diminishing immune memory to the first organism. The benefits of heterologous infections to the immune system, however, carry within them a potential downside: a second or tertiary infection may alter $\mathrm{T}$ cell hierarchy in such a way that self-reactive, initially subdominant $\mathrm{T}$ cell populations generated during previous infections are expanded, leading to enhanced immunopathology and autoimmune disease. We investigated here whether activation and expansion of autoreactive lymphocyte populations can occur after interaction with lower-avidity viral ligands that mimic self ligands and whether this might lead to clinical disease after repeated stimulation with heterologous viral infections and/or within an already established local inflammatory environment (28) within the target organ. The rat insulin promoter-lymphocytic choriomeningitis virus-nucleoprotein (RIP-LCMV-NP) transgenic mouse model of autoimmune diabetes, in which the NP from LCMV is expressed transgenically as a self antigen in pancreatic $\beta$ cells as well as the thymus, coupled with LCMV infection leads to LCMV-specific 
Table 1

CD8 T cell epitopes of LCMV-NP and PV-NP

\begin{tabular}{|c|c|c|c|}
\hline \multicolumn{4}{|c|}{ Immunodominant NP epitopes } \\
\hline LCMV-Arm & $\mathrm{NP}_{396-404}$ & FQPQNGQFI & $H-2 D^{b}$ \\
\hline Pichinde virus & $\mathrm{NP}_{16-25}$ & RGLSNWTHPV & $H-2 D^{b}$ \\
\hline Pichinde virus & $\mathrm{NP}_{38-45}$ & SALDFHKV & $\mathrm{H}-2 \mathrm{~K}^{\mathrm{b}}$ \\
\hline Pichinde virus & $\mathrm{NP}_{122-132}$ & VYEGNLTNTQL & $H-2 D^{b}$ \\
\hline \multicolumn{4}{|c|}{ Subdominant NP epitopes } \\
\hline LCMV-Arm & $\mathrm{NP}_{205-212}$ & YTVKYPNL & $\mathrm{H}-2 \mathrm{~K}^{\mathrm{b}}$ \\
\hline Pichinde virus & $\mathrm{NP}_{205-212}$ & YTVKFPNM & $\mathrm{H}-2 \mathrm{~K}^{\mathrm{b}}$ \\
\hline \multicolumn{4}{|l|}{ Other epitopes } \\
\hline LCMV-Arm-Var & $\mathrm{NP}_{396-404}$ & FQPQNGQLI & $H-2 D^{b}$ \\
\hline LCMV-Arm & $\mathrm{GP}_{33-41}$ & KAVYNFATC & $H-2 D^{b}$ \\
\hline
\end{tabular}

Immunodominant and subdominant CD8 T cell epitopes of LCMV-NP and PV-NP are shown with their individual MHC restrictions. Amino acids shared between LCMV-NP 205 and PV-NP 205 are underlined.

autoreactive CD8 and CD4 lymphocytes (29) that initiate the destruction of $\beta$ cells (30). Islet destruction requires both perforin and IFN- $\gamma$ (31). Importantly, in these mice, the full autoimmune process in the islets develops after the systemic antiviral $\mathrm{T}$ cell response to the triggering virus (LCMV) has receded and virus has been cleared. At that time, antibodies against other islet antigens like insulin and glutamic acid decarboxylase appear. Thymic expression of the viral protein leads to elimination of the majority of the LCMV-NP-specific autoreactive CD8 T cells, resulting in a slower disease development that requires both CD4 and CD8 T cells (29). Thus, the viral NP, which is genetically passed to progeny mice, acts like a true self antigen in RIP-LCMV mice. One can envision a similar scenario in humans affected by T1D: we know that many islet antigens are expressed in the thymus; consequent$l y$, the numbers and/or avidity of autoreactive lymphocytes are low and viral infections that affect the pancreas, among other organs, are not infrequent.

We found here that heterologous sequential viral infections can augment autoreactive cross-reactive $T$ lymphocytes in the target organ above the disease-initiating threshold (32), so that major tissue injury and diabetes develop much more rapidly. The outcome of our study here clearly demonstrates that cross-reactivity between viral and self epitopes can augment but not initiate autoimmune disease in this model. In addition, our studies show that the infectious agent essential for initiating the autoimmune process can be cleared by the host immune response prior to a secondary virus infection, which is responsible for the disease acceleration. The resulting more rapid diabetes development occurs only if the secondary infection takes place during the prediabetic phase, but not in healthy, unprimed animals. Thus, in humans, disease acceleration could be the result of the combined effect of a few to several immunological cross-reactive viruses.

\section{Results}

Challenge of unprimed, naive animals with viruses that express lower-avidity mimic ligands of $\beta$-cell epitopes fails to induce autoimmune diabetes. Infection of RIP-LCMV-NP H-2 $2^{\mathrm{b}}$ transgenic mice, which express the LCMV strain Armstrong (LCMV-Arm) NP protein (LCMV-NP) in $\beta$ cells, with LCMV-Arm leads to T1D 2-4 months after infection in more than $95 \%$ of mice. By 10-14 days after LCMV infection, virus is cleared from infected mice (29). In order to identify the $\mathrm{T}$ cell epitopes of the viral NP molecule responsible for induc- tion of diabetes, we infected transgenic mice with LCMV-Arm that contains LCMV-NP ${ }_{396}$ and LCMV-NP 205 cytotoxic $\mathrm{T}$ cell epitopes or with an LCMV-NP ${ }_{396}$ cytotoxic T lymphocyte (CTL) escape variant (LCMV-Arm escape variant; LCMV-Arm-Var) that contains a single amino acid substitution of phenylalanine to leucine at position 403 (substitution underlined: FQPQNGQFI to FQPQNGQLI; Table 1) (33). While infection with LCMV-Arm caused diabetes with the expected kinetics, infection with LCMV-Arm-Var, which lacked the LCMV-NP ${ }_{396}$ epitope but still expressed the normal LCMV-NP 205 epitope (33), did not (Figure 1A). Thus, the LCMV$\mathrm{NP}_{396}$ epitope that is recognized with comparatively high avidity (34) was essential for initiation of T1D in RIP-NP H-2 $2^{\mathrm{b}}$ mice.

To assess the contribution of the LCMV-NP ${ }_{205} \mathrm{CD} 8 \mathrm{~T}$ cell epitope for induction of diabetes, we utilized Pichinde virus (PV), another member of the arenavirus family, which contains the cross-reactive $\mathrm{H}-2 \mathrm{~K}^{\mathrm{b}}$-restricted epitope PV-NP 205 , YTVKFPNM, that shares six of eight amino acids with the LCMV-NP 205 epitope, YTVKYYPNL (substitutions underlined; Table 1) (27). Although binding of the LCMV-NP 205 and PV-NP 205 epitopes to $\mathrm{H}-2 \mathrm{~K}^{\mathrm{b}}$ was similar (despite differences in the MHC anchoring residues at positions 209 and 212), they exhibited differential antigenic properties. PV infection elicited more CD8 T cells to the PV-NP 205 than to the LCMV-NP 205 epitope in earlier studies (27), indicating that true cross-reactivity of the interaction of the $\mathrm{NP}_{205}$-peptide presented by MHC class I in conjunction with TCR was operational rather than reduced binding affinity of the mimic peptide to MHC. Despite the presence of this cross-reactivity with the LCMV-NP transgene, infection of transgenic mice with PV failed to induce diabetes (Figure 1A). This lack of disease induction was likely associated with the approximately 100 -fold lower avidity of PV-NP 205 compared with LCMV$\mathrm{NP}_{396}$ in cytotoxicity assays (27), resulting in a failure to induce a robust primary CD8 T cells response to the lower-avidity $\mathrm{PV}-\mathrm{NP}_{205}$ after LCMV infection. Collectively, these data indicate that upon infection of RIP-LCMV-NP mice with LCMV-Arm, induction of diabetes is dependent on the higher-avidity $\mathrm{H}-2 \mathrm{D}^{\mathrm{b}}$-restricted LCMV-NP ${ }_{396}$ epitope and not the lower-avidity $\mathrm{H}-2 \mathrm{~K}^{\mathrm{b}}$-restricted LCMV-NP 205 epitope. Based on this study (Figure 1A) and previous studies (35), we conclude that naturally occurring viral mimics recognized with comparatively lower avidity are unable to activate a sufficient number of naive autoreactive lymphocytes to cause clinical diabetes, even if the infecting virus is tropic to the pancreas and induces local inflammation of the target organ $(36,37)$.

A lower-avidity viral mimic ligand of a $\beta$-cell CD8 T cell epitope can significantly accelerate an ongoing autoimmune process and the development of clinical disease. We next asked whether the lower-avidity LCMV$\mathrm{NP}_{205}$ epitope could influence the diabetic outcome of mice in the prediabetic stage in which autoreactive processes were already established. We addressed this question through the use of sequential heterologous infections of transgenic mice with LCMV-Arm and PV separated by a 4-week interval. As described earlier (27), immunity to PV exhibits clear cross-reactivity of the PV epitope PV-NP 205 to the LCMV-NP epitope LCMV-NP 205 . Indeed, as shown in Figure 1B, PV infection administered 1 month after the initial autoimmunity-initiating LCMV infection considerably accelerated T1D in RIP-LCMV-NP mice. Importantly, the PV infection had to occur at a time when islet destruction was already ongoing (initiated by LCMV infection 4 weeks earlier), as the reverse scenario (when PV was given first followed by secondary PV or LCMV infection) did not accelerate T1D (Figure 1B). This observation shows that PV can enhance LCMV-induced T1D in RIP-LCMV-NP mice 
A

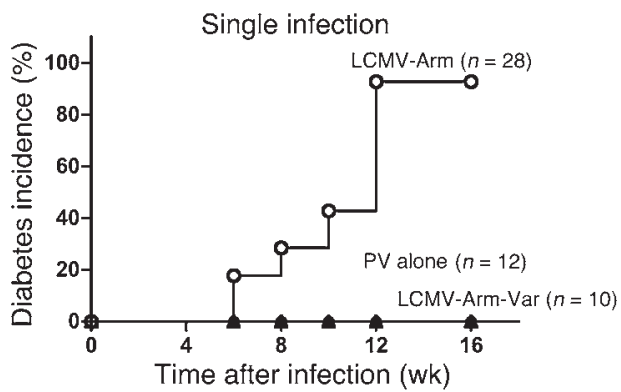

B

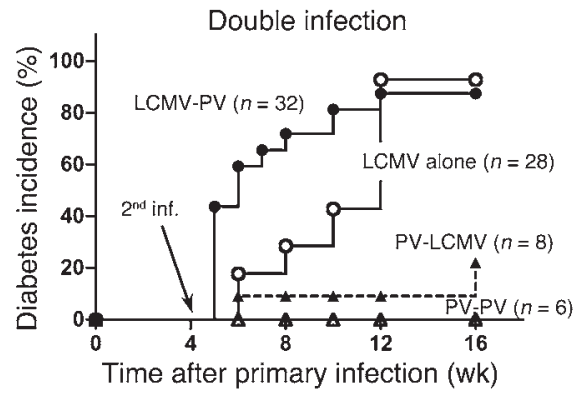

when given after but not before the initiation of islet destruction by LCMV-NP ${ }_{396}$-specific CTLs.

To define the precise role of cross-reactive CD8 T cells that specifically react to the $\mathrm{NP}_{205}$ epitope of LCMV and PV (LCMV/PV$\mathrm{NP}_{205}$-specific cross-reactive CD8 T cells) in these different infection scenarios, we quantified their numbers and functional activity after primary and secondary PV and LCMV infection, respectively. Figure 2 shows the frequencies of IFN- $\gamma$-producing CD8 T cells in response to the LCMV H-2 $\mathrm{D}^{\mathrm{b}}$-restricted LCMV-NP 396 and dominant LCMV-glycoprotein 33 (LCMV-GP 33 ) peptides, the LCMV cross-reactive subdominant $\mathrm{H}-2 \mathrm{~K}^{\mathrm{b}}$-restricted LCMV-NP 205 peptide, and the $\mathrm{PV}$ dominant $\mathrm{PV}-\mathrm{NP}_{38}$ peptide (internal $\mathrm{PV}$ control) after primary LCMV or PV infection and after secondary infection with LCMV or PV. As expected, primary and secondary PV infection expanded the dominant $\mathrm{PV}-\mathrm{NP}_{38}$-specific population (Figure 2B). Furthermore, as described earlier (29), infection of RIP-LCMV-NP mice with LCMV alone resulted in high numbers of LCMV-GP ${ }_{33}-$ specific $\mathrm{CD} 8 \mathrm{~T}$ cells but much lower numbers of $\mathrm{LCMV}-\mathrm{NP}_{396}$-specific CD8 T cells, as this mouse line expresses LCMV-NP in the thymus as well as in the pancreas, resulting in thymic negative selection of a significant proportion of NP-specific CD8 T cells. The slower development of disease in RIP-LCMV-NP mice than in RIP-LCMVGP mice (38) can be attributed to this fact. Important for our investigation here is that secondary PV infection in LCMV-infected RIP-LCMV-NP mice strongly and selectively expanded the LCMV$\mathrm{NP}_{205}$-specific CD8 $\mathrm{T}$ cell population but none of the other LCMVspecific populations ( $L C M V-\mathrm{GP}_{33}$ and LCMV-NP ${ }_{396}$ ). This finding indicates that $\mathrm{LCMV} / \mathrm{PV}-\mathrm{NP}_{205}$-specific cross-reactive $\mathrm{CD} 8 \mathrm{~T}$ cells are alone not sufficient to cause T1D in RIP-LCMV-NP mice but are important for the acceleration of disease observed after secondary PV infection. Most likely they must be present in islets together with LCMV-NP ${ }_{396}$-specific CD8 $\mathrm{T}$ cells in order to cause disease, as diabetes never developed after single PV infection (Figure 1A). The selective expansion of LCMV/PV-NP ${ }_{205}$-specific cross-reactive CD8 $\mathrm{T}$ cell populations is in concordance with observations of Brehm et al. (27) and strengthens the hypothesis that PV-NP ${ }_{205}$-specific

\section{Figure 1}

Molecular mimicry can accelerate but not easily initiate autoimmune diabetes. (A) Molecular mimicry is insufficient to prime naive autoreactive CD8 T cells and cause autoimmune diabetes. RIPLCMV-NP mice were infected with $10^{5}$ PFU LCMV-Arm (open circles), LCMV-Arm-Var (filled triangles), or PV alone (filled circles). (B) Primed autoreactive cells can become activated via molecular mimicry and accelerate disease. RIP-LCMV-NP mice were infected with either $10^{5}$ PFU LCMV-Arm (open circles, filled circles) or $10^{5}$ PFU PV (open triangles, filled triangles) on day 0 and, as indicated, received a secondary inoculation (2nd inf.) with PV (open triangles, filled circles) 28 days after the priming LCMV infection. As a comparison, the incidence data to RIP-LCMV-NP mice infected with LCMV alone are displayed (open circles). For both studies, blood glucose values were determined at weekly intervals. Mice with blood glucose levels above $300 \mathrm{mg} / \mathrm{dl}$ were considered diabetic. It is evident from these studies that secondary infection but not primary infection with PV can accelerate T1D development. Statistical analysis was done using the log rank test. Note that the diabetes onset curves for the groups LCMV alone versus LCMVPV are significantly different $(P=0.0066)$.

CD8 $\mathrm{T}$ cells play a role in the acceleration of diabetes in mice with preclinical diabetes. Challenge of mice immune to LCMV (LCMVimmune mice) with a secondary LCMV infection did not result in a long-lasting expansion of either LCMV-NP 396 -specific or LCMV$\mathrm{NP}_{205}$-specific cross-reactive CD8 $\mathrm{T}$ cell populations (Figure 2B). This stands well in agreement with our earlier findings that sequential infection with LCMV-Arm has no influence on the incidence and kinetics of diabetes in RIP-LCMV-NP mice (39).

We further investigated whether the expansion/activation of previously primed LCMV/PV-NP 205 -specific CD8 $\mathrm{T}$ cell populations by the mimic epitope expressed by PV enhanced the effector functions of these cells. Primary infection of C57BL/ 6 wild type or RIP-LCMV-NP mice with PV induced no detectable CD8 $\mathrm{T}$ cells response to whole LCMV-NP protein (Table 2). However, PV-challenged, LCMV-primed mice made clearly detectable recall responses to whole LCMV-NP, as evidenced by killing assays (Table 2), and to LCMV-NP ${ }_{205}$ as shown by intracellular cytokine staining for IFN- $\gamma$ by flow cytometry (Figure 2C). In agreement with the results presented in Figure $2 \mathrm{C}$ is the substantially increased number of PV-NP 205 CTL precursors in mice that received LCMV and then PV sequentially (Figure 2D). Thus, expansion of LCMV/ PV-NP 205 cross-reactive CD8 T cell populations with lytic activity (31) and IFN- $\gamma$ production occurs after PV infection only in LCMV-immune mice.

Sequential infection with $L C M V$ and $P V$ results in accumulation of $P V-N P_{205}$-specific CD8 T cells in islets. Histological examination of the pancreas at week 3 after secondary infection of LCMV-primed RIPLCMV-NP mice with PV revealed increased lymphocyte infiltration and destruction of the islets of Langerhans (Figure 3A, lower left panel). There was profound difference in islet infiltration by CD8 $T$ cells in these mice versus mice that had only been administered a single LCMV infection (Figure 3A, upper left panel).

A critical component of the hypothesis that LCMV/PV-NP ${ }_{205^{-}}$ specific cross-reactive CD8 $\mathrm{T}$ cells participate in the acceleration of diabetes is the identification of these cells at the right time and place after secondary $\mathrm{PV}$ infection in relation to the pancreas 

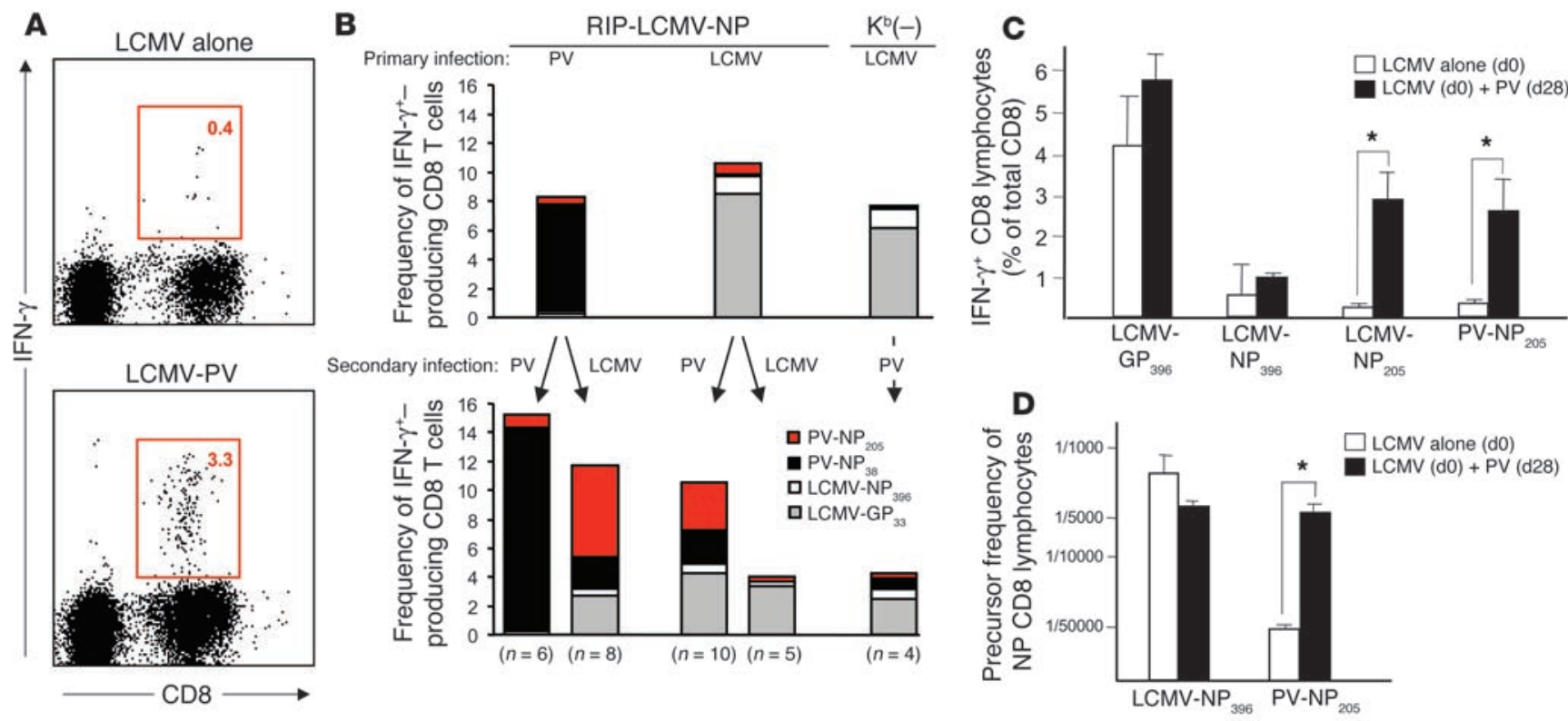

\section{Figure 2}

CD8 T cell populations specific for the mimicking epitope PV-NP 205 are significantly expanded after sequential infection with PV. (A and B) RIPLCMV-NP and RIP-LCMV-NP $\times \mathrm{K}^{\mathrm{b}}(-)$ mice were infected with $10^{5}$ PFU LCMV or PV. After 4 weeks, the mice received a secondary infection of either LCMV or PV. (A) Intracellular cytokine staining (ICCS) after stimulation with PV-NP 205 is displayed for 1 representative mouse infected first with LCMV (LCMV alone) and then with PV (LCMV-PV) (mean frequencies are indicated in boxed areas). (B) The frequency of epitope-specific CD8 T cells in the blood was determined by ICCS for IFN- $\gamma$ after stimulation with the indicated peptides (key) immediately before (upper panel) and 7 days after (lower panel) secondary infection. (C) Numbers of $\mathrm{H}-2 \mathrm{~K}^{\mathrm{b}}$-restricted PV-NP $205-$ specific lymphocytes after LCMV or PV infection, assessed by ICCS for IFN- $\gamma$. Splenocytes were harvested on day 35 from mice that received LCMV at day 0 (d0) and, for the PV group, PV at day 28 (d28). Means ( \pm SEM) are displayed. (D) Lytic precursors after LCMV-NP 396 versus PV-NP 205 antigenic stimulation for 10 days. In addition to lytic activity, IFN- $\gamma$ production was assessed in the supernatant of each well; wells with IFN- $\gamma$ levels of $\mathrm{more}$ than $0.05 \mathrm{ng} / \mathrm{ml}$ by ELISA were counted as positive. IFN- $\gamma$ production was on average $13( \pm 3.5) \mathrm{ng} / \mathrm{ml}$ in LCMV-NP ${ }_{396}-$ stimulated cultures and $7.1( \pm 3.1) \mathrm{ng} / \mathrm{ml}$ in PV-NP ${ }_{205}-$ stimulated cultures. This experiment was repeated three times and mean values $( \pm \mathrm{SEM})$ are displayed. ${ }^{*} P<0.05$.

and, more specifically, the target of the autoimmune response (the islets of Langerhans). Thus, we generated $\mathrm{H}-2 \mathrm{~K}^{\mathrm{b}}-\mathrm{PV}-\mathrm{NP}_{205}$ tetramers in attempt to perform in situ tetramer staining for $\mathrm{PV}-\mathrm{NP}_{205}$-specific CD8 T cells in quick-frozen pancreas sections, similar to what we previously reported for $\mathrm{LCMV}-\mathrm{GP}_{33}$-specific CD8 T cells in the CNS (40). Histological examination using specific immunohistochemical staining for CD8 T cells and selective $\mathrm{H}-2 \mathrm{~K}^{\mathrm{b}}-\mathrm{PV}-\mathrm{NP}_{205}$ tetramer staining on tissue sections for $\mathrm{NP}_{205^{-}}$ specific CD8 T cells revealed that PV-NP ${ }_{205}$ CD8 T cells were present exclusively in islets of mice initially primed with LCMV and secondarily infected with PV. Between 1 and 3 PV-NP ${ }_{205}$-specific CD8 T cells were found in about $50 \%$ of all islet sections analyzed. In contrast, none of the islet sections examined in mice infected with LCMV alone contained any PV-NP $\mathrm{N}_{205}$-specific CD8 T cells (Figure 3A, upper right panel). Quantification of our data indicated that a frequency of $2-4 \%$ of all infiltrating CD8 T cells were $\mathrm{PV}-\mathrm{NP}_{205}$ specific in sequentially infected mice, which reflected the frequencies displayed in Figure 3B, assessed by flow cytometry in peripheral lymphoid organs, and corroborated frequencies of isletinfiltrating $\mathrm{GP}_{33}$-specific CD8 $\mathrm{T}$ cells observed both in the RIPLCMV-GP fast-onset diabetes model (GP not expressed in thymus) using H-2D ${ }^{\mathrm{b}}-\mathrm{LCMV}-\mathrm{GP}_{33}$ tetramers (D.B. McGavern, unpublished results) and in LCMV-mediated leptomeningitis (40).

The expansion of LCMV/PV-NP ${ }_{205}$-specific cross-reactive CD8 $\mathrm{T}$ cell populations was also demonstrated by flow cytometry after staining with $\mathrm{H}-2 \mathrm{~K}^{\mathrm{b}}-\mathrm{PV}-\mathrm{NP}_{205}$ tetramers (Figure $3 \mathrm{~B}$ ) and intracellular cytokine staining for IFN- $\gamma$ (Figure 3B, lower panels) in the blood as well as in the pancreatic draining lymph nodes (PDLNs) after sequential infection of transgenic mice with LCMV and PV. In particular, in the PDLNs, $\mathrm{H}-2 \mathrm{~K}^{\mathrm{b}}-\mathrm{PV}-\mathrm{NP}_{205}$ tetramer ${ }^{+} \mathrm{CD} 8 \mathrm{~T}$ cell populations expanded to a frequency of $4 \%$ after secondary $\mathrm{PV}$ infection, compared with only $0.4 \%$ after a single LCMV infection (Figure $3 \mathrm{~B})$. Thus, if PV infection occurs after LCMV infection, a selective and considerable expansion of initially subdominant, lower-avidity $\mathrm{LCMV} / \mathrm{PV}-\mathrm{NP}_{205}$-specific cross-reactive CD8 $\mathrm{T}$ cell populations is seen in the target organ and PDLNs.

Activation of LCMV/PV-NP 205 -specific cross-reactive CD8 T cells through molecular mimicry is absolutely essential for acceleration of diabetes and does not occur in mice genetically deficient in $\mathrm{H}-2 \mathrm{~K}^{b}$ and in mice that were tolerized to $P V-N P_{205}$. Further evidence that $\mathrm{LCMV} / \mathrm{PV}-\mathrm{NP}_{205}-$ specific cross-reactive CD8 $\mathrm{T}$ cells were responsible for the acceleration of T1D was obtained from experiments using RIP-LCMV-NP mice bred onto a $\mathrm{H}-2 \mathrm{~K}^{\mathrm{b}}$-deficient $\left[\mathrm{K}^{\mathrm{b}}(-)\right]$ background (41). Because these mice still present the LCMV-NP ${ }_{396}$ epitope, which is $\mathrm{H}-2 \mathrm{D}^{\mathrm{b}}$ restricted, diabetes still occurred with the expected slower kinetics after a single LCMV infection (data not shown). However, sequential infection of these mice with LCMV followed by PV did not result in accelerated disease, which occurred as expected in RIP-LCMV$\mathrm{NP} \times \mathrm{H}-2 \mathrm{~K}^{\mathrm{b}}$-sufficient $\left[\mathrm{K}^{\mathrm{b}}(+)\right]$ littermates (Figure $\left.4 \mathrm{~A}\right)$. Overall, the incidence of T1D in RIP-LCMV-NP $\times \mathrm{K}^{\mathrm{b}}(+)$ littermates mice was lower and its kinetics slower than in the original RIP-LCMV-NP line, because background genes introduced by the SV129 embry- 
onic stem cells from knockout lines are known to protect from T1D in RIP-LCMV mice (42). In contrast to RIP-LCMV-NP $\times \mathrm{K}^{\mathrm{b}}(+)$ littermates, RIP-LCMV-NP $\times \mathrm{K}^{\mathrm{b}}(-)$ mice did not have accelerated T1D after secondary PV infection. In parallel with the lack of acceleration of diabetes in the RIP-LCMV-NP $\times \mathrm{K}^{\mathrm{b}}(-)$ mice, secondary infection with PV did not result in expansion of LCMV/PV-NP ${ }_{205^{-}}$ specific CD8 $\mathrm{T}$ cell populations (Figure $2 \mathrm{~B}$, right column) or in enhanced islet infiltration (Figure 4B).

Furthermore, RIP-LCMV-NP mice that were tolerized to the PV-NP 205 epitope showed no acceleration of T1D after secondary infection with PV (Figure 4C). Tolerization to PV-NP 205 was achieved by i.v. injection of PV-NP $\mathrm{N}_{205}$-coated splenocytes that were cross-linked with 1-ethyl-3-(3-dimethylaminopropyl)-carbodiimide $(\mathrm{EDCI})(43,44)$. Mice that were treated with $2 \times 10^{7}$ syngeneic EDCI-PV-NP 205 cross-linked splenocytes 5 days before primary LCMV infection did not display accelerated T1D after subsequent infection with PV 1 month after infection with LCMV (Figure 4C). In contrast, mice that received splenocytes that were cross-linked with EDCI in absence of PV-NP 205 displayed accelerated T1D after secondary infection as usual (Figure 4C). These experiments are consistent with the necessity of $\mathrm{H}-2 \mathrm{~K}^{\mathrm{b}}$-restricted $\mathrm{NP}_{205}$-specific $\mathrm{T}$ cells in the acceleration of T1D.

LCMV/PV-NP $205-$ specific cross-reactive CD $8 \mathrm{~T}$ cell populations expand and accelerate disease in LCMV-immune mice challenged with PV-NP 205 peptide and polyinosinic-polycytidylic acid. Final evidence that LCMV/ PV-NP ${ }_{205}$-specific cross-reactive CD8 T cells are responsible for the acceleration of T1D was obtained from experiments using RIPLCMV-NP mice that were administered PV-NP 205 peptide together with synthetic polyinosinic-polycytidylic acid [poly(I:C)], a "mimic" of double-stranded viral RNA (Figure 4, D and E). LCMV/PV-NP $205^{-}$ specific CD8 $\mathrm{T}$ cell populations were significantly expanded in LCMV-immune RIP-LCMV-NP mice that received $100 \mu \mathrm{g}$ PV-NP 205 peptide (i.p.) together with a single injection of $7.5 \mu \mathrm{g}$ poly(I:C) per gram body mass (i.p.) at week 4 after LCMV infection (Figure 4D). The frequency of LCMV/PV-NP 205 -specific CD8 T cells was much higher than after administration of the irrelevant $\mathrm{H}-2 \mathrm{~K}^{\mathrm{b}}$-binding OVA peptide SIINFEKL followed by poly(I:C) or PV-NP 205 alone and even exceeded the frequency observed when LCMV-immune mice received a secondary infection with PV (Figure 4D). As expected, T1D was accelerated in mice treated with PV-NP205 plus poly(I:C) in a way similar to that in mice that received a secondary $\mathrm{PV}$ infection (Figure 4E). Mice that were administered OVA peptide (SIINFEKL) and poly(I:C) had hyperglycemia (mean blood glucose value of $225 \mathrm{mg} / \mathrm{dl}$ ) but no diabetes (Figure 4E). Furthermore, treatment with PV-NP 205 alone did not accelerate diabetes (Figure 4E). These data demonstrate that in the proper inflammatory environment, the $\mathrm{NP}_{205}$ epitope that confers molecular mimicry between LCMV and PV is sufficient to accelerate autoimmune diabetes and requires no further assistance by other LCMV and/or PV epitopes.

\section{Discussion}

In this study we have provided evidence that the expansion of previously primed autoreactive $\mathrm{T}$ cell populations via heterologous virus infections and molecular mimicry can lead to the acceleration of autoimmune diabetes in prediabetic hosts but not to de novo induction of diabetes in naive mice. We have identified the cellular factors responsible for disease acceleration in the H-2 ${ }^{\text {b }}$ RIP-LCMV-NP diabetes model and have shown that the mechanism involves the expansion/activation and participation in islet destruction of previously primed $\mathrm{CD} 8 \mathrm{~T}$ cell populations specific for the subdominant $\mathrm{NP}_{205}$ epitope. Important for understanding the pathogenesis of human autoimmune diabetes are (a) our findings that molecular mimicry alone, in the context of arenavirus infection, is not likely to lead to autoimmune diabetes, unless islet inflammation is already present (prediabetic, ongoing disease state), and (b) the fact that heterologous viral infections can expand $T$ cell populations with lower-avidity autoreactive specificities that are unable to initiate disease themselves after a single infection. With regards to the association of sequential viral infections with the pathogenesis of human T1D, our conclusions indicate the following possible scenario: a viral infection necessary for the initiation of T1D can be cleared prior to a second virus infection mimicking an autoantigen. Such a sequential infection(s) can occur after a relative long latency period. It is important to note that the clinical manifestation of T1D requires more than $90 \%$ of all $\beta$ cells to be destroyed, whereas the clinical manifestation of CNS disease (manuscript submitted for publication) occurs at comparably much lower degrees of destruction. This might explain why virally expressed mimics cannot precipitate diabetes in naive mice, whereas they can cause significant damage in a model of virally induced CNS inflammatory disease (manuscript submitted for publication).

What are the implications of our observations for the role of molecular mimicry in autoimmune disease? Previously published findings in our model systems indicate that LCMV-GP ${ }_{33}$-specific CD8 $\mathrm{T}$ cells that are of comparable avidity to $\mathrm{LCMV} / \mathrm{PV}-\mathrm{NP}_{205^{-}}$ specific cross-reactive CD8 T cells can induce disease; thus, avidity alone does not determine the ability of an epitope to initiate autoimmune diabetes. One must additionally consider that there is a critical threshold number of autoreactive lymphocytes required (32), short of which clinical disease cannot develop. Therefore, the cross-reactive immune response to an autoanti-

\section{Table 2}

Cytotoxic T cells specific for LCMV-NP are found in LCMV-immune but not naive mice after PV infection

LCMV (day 0) + PV (day 42)
C57BL/6J (day 7 after PV)
RIP-LCMV-NP (day 7 after PV)
RIP-LCMV-NP (day 28 after PV)
2 wk stimulation on LCMV APCs
RIP-LCMV-NP (day 28 after PV)
2 wk stimulation on PV APCs
LCMV alone
C57BL/6J (day 7 after LCMV)
PV alone

C57BL/6J (day 7 after PV)

\begin{tabular}{cccccc}
\multicolumn{5}{c}{ Specific } & \multicolumn{5}{c}{ 51 release from H-2 ${ }^{\mathrm{b}}$ targets infected with: } & \\
E:T & LCMV & PV & LCMV-GP & LCMV-NP & T1D dev. \\
$50: 1$ & $14 \pm 2$ & $30 \pm 4$ & ND & ND & No \\
$50: 1$ & $15 \pm 4$ & $32 \pm 4$ & ND & ND & No \\
$5: 1$ & $35 \pm 8$ & 0 & $25 \pm 6$ & $15 \pm 4$ & Yes \\
$5: 1$ & $12 \pm 4$ & $20 \pm 6$ & $10 \pm 3$ & $11 \pm 4$ & Yes \\
& & & & & \\
$50: 1$ & $45 \pm 8$ & 0 & $23 \pm 7$ & $34 \pm 8$ & No \\
$50: 1$ & 0 & $20 \pm 7$ & 0 & 0 & No
\end{tabular}

Primary ex vivo cytotoxic T lymphocyte activities were determined 7 days after LCMV or PV infection as described in Methods. Secondary in vitro stimulation was performed where indicated using LCMV- or PV-infected irradiated APCs. E:T, effector/target; T1D dev., development of T1D; ND, not determined. 
A
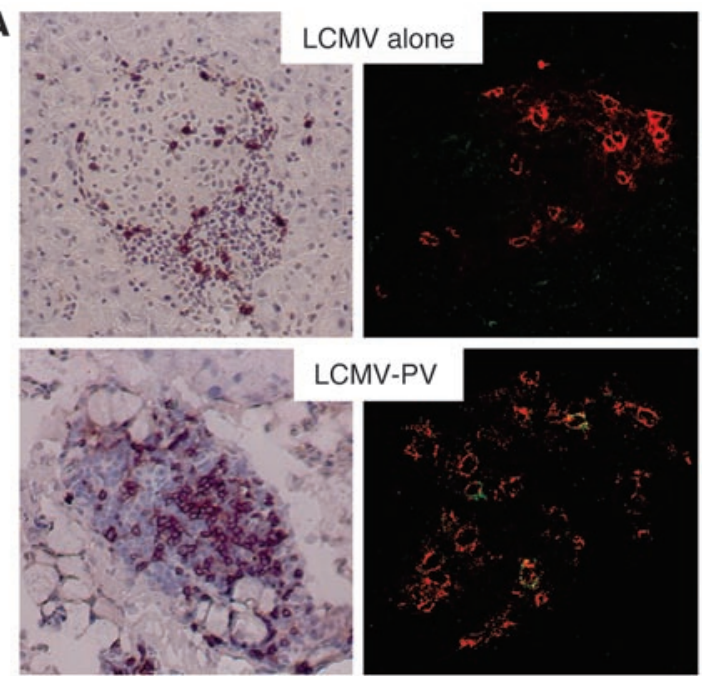

B
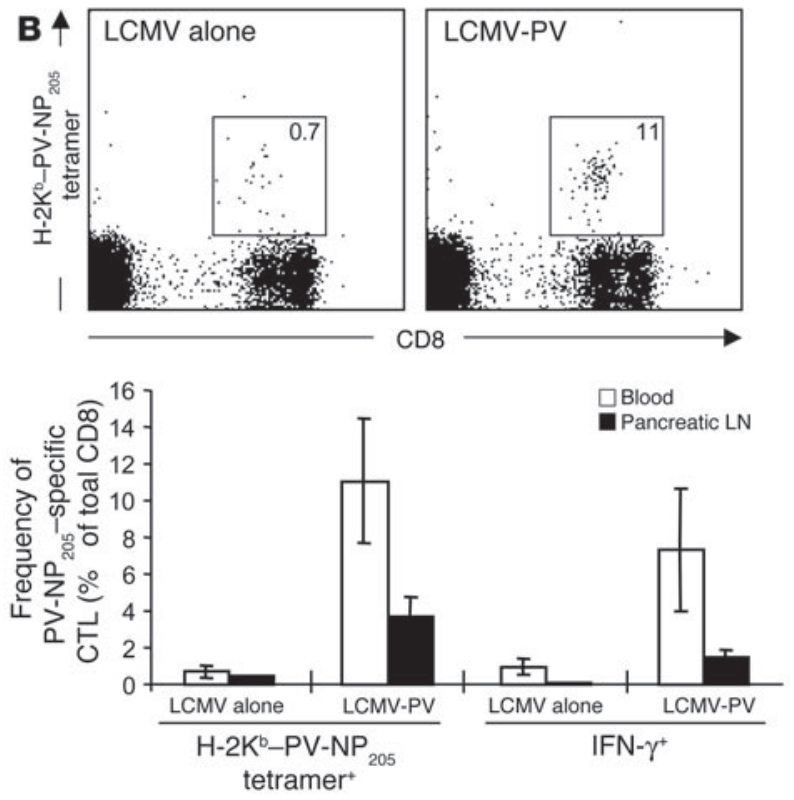

gen elicited by an infectious agent conferring molecular mimicry would have to be of sufficient magnitude, avidity, and/or persistence in order to become clinically relevant and precipitate disease in a healthy individual not predisposed to autoimmune disease. The failure of the $\mathrm{NP}_{205}$ mimic epitope to initiate autoimmune disease is not a property restricted to subdominant epitopes, because the numbers of LCMV/PV-NP 205 -specific cross-reactive $\mathrm{CD} 8 \mathrm{~T}$ cells were about equal to the numbers of LCMV-NP ${ }_{396}$-specific CD8 T cells in RIP-LCMV-NP mice (Figure 2). Thus, the usually subdominant LCMV-NP 205 epitope (in C57BL $/ 6 \mathrm{H}-2^{\mathrm{b}}$ mice) is not subdominant in RIP-LCMV-NP mice that express NP in the thymus in addition to the pancreas. This can be explained by the fact that thymic selection affects selectively epitopes with higher functional avidity, as demonstrated by us previously in the RIP-LCMV thymic expresser mice (45). In addition, a mimic of a dominant epitope showed similar results. Infection of H-2d RIP-LCMV-NP mice with LCMV strain Pasteur (LCMV-Past), which carries a mutation of the dominant $\mathrm{L}^{\mathrm{d}}$-restricted LCMV-Arm-NP ${ }_{118}$ CD8 epitope (35), also failed to

\section{Figure 3}

Sequential infection with LCMV and PV results in accumulation of PV$\mathrm{NP}_{205}$-specific CD8 T cells in the islets of Langerhans. (A) RIP-NP mice were infected with $10^{5}$ PFU LCMV. After 4 weeks, one group of mice received a secondary infection of PV (105 PFU, i.p.). Left panels, pancreata were harvested at week 3 after secondary infection and 6- $\mu \mathrm{m}$ tissue sections were stained for cellular infiltration with a monoclonal antibody against CD8. Sections were counterstained with hematoxylin. Right panels, pancreata were harvested at day 5 after secondary infection and $6-\mu \mathrm{m}$ tissue sections were cut and were stained for CD8 T cells with rhodamine X-conjugated anti-CD8 (red) and for PV-NP 205 -specific CD8 T cells with allophycocyanin-conjugated $\mathrm{H}-2 \mathrm{~K}^{\mathrm{b}}-\mathrm{PV}-\mathrm{NP}_{205}$ tetramers (green). Note that only after sequential infection with LCMV followed by PV are PV-NP ${ }_{205}$-specific CD8 T lymphocytes (yellow) found in the islets of Langerhans. Original magnification, $\times 20$. (B) Expansion of PV-NP $205-$ specific CD8 T cell populations in blood and pancreatic lymph nodes after secondary PV infection. Upper panels, flow cytometry of PV-NP ${ }_{205}$-specific CD8 T cells in the blood of LCMV-immune mice that did or did not receive secondary infection with PV, as detected by $\mathrm{H}-2 \mathrm{~K}^{\mathrm{b}}-\mathrm{PV}-\mathrm{NP}_{205}$ tetramers; mean frequencies are indicated in boxed areas. Lower panel, frequencies of PV-NP ${ }_{205}$-specific CD8 T cells were determined by flow cytometry using $\mathrm{H}-2 \mathrm{~K}^{\mathrm{b}}-\mathrm{PV}-\mathrm{NP}_{205}$ tetramer staining and by ICCS for IFN- $\gamma$ expression after 5 hours of in vitro stimulation with $\mathrm{PV}^{-\mathrm{NP}_{205}}$ peptide.

develop diabetes, in contrast to mice infected with LCMV-Arm (32). The LCMV-Past mimic epitope, like PV-NP ${ }_{205}$, was found to be of low avidity compared with the wild-type epitope. Taken together, those previous results and our observations here indicate that the important factors in determining the ability to initiate autoimmune pathology are epitope avidity and numbers of CD8 T cells induced. Molecular mimicry appears therefore less likely to precipitate autoimmune diabetes de novo in healthy individuals with no preexisting islet damage (Figure 1).

Alternatively, as shown here, CD8 $\mathrm{T}$ cells specific for mimic foreign or self ligand that are incapable of initiating disease by themselves may become dangerous if they encounter a "fertile field" of ongoing inflammatory responses (28). Such a scenario can be envisioned in the presence of a persistent infection in which a chronic inflammatory milieu drives the activation and expansion of cross-reactive $T$ cell populations, as in animal models of murine herpesvirus 1-induced (HSV-1-induced) herpes stromal keratitis (HSK) (25) and in recombinant Theiler murine encephalomyelitis virus-induced (TMEV-induced) demyelination (20). Indeed, infection of mice with a HSV-1 mutant virus with a single amino acid change in the UL6 protein of HSV-1 affecting the putative mimicry epitope failed to induce HSK. However, the mutant HSV-1 was able to induce disease in predisposed mice that received CD4 cells from donors infected with wild-type virus (25). In the TMEV model, recent data suggest that a molecular mimic of an encephalitogenic myelin proteolipid epitope, when expressed by an engineered TMEV, can both initiate CNS autoimmune disease and exacerbate a previously established disease (manuscript submitted for publication). However, our model differs significantly from those two other experimental systems in that diabetes manifestation requires destruction of around $90 \%$ of $\beta$ cells. In contrast to MS, we have demonstrated for diabetes that the enhancement of disease requires at least two consecutive acute viral infections that can be nonpersistent. In our case, LCMV-NP ${ }_{396}$-specific CD8 $\mathrm{T}$ cells (Figure 2 ) were essential for the precipitation of disease (Figure 1) and contributed to providing an inflammatory milieu in 
A
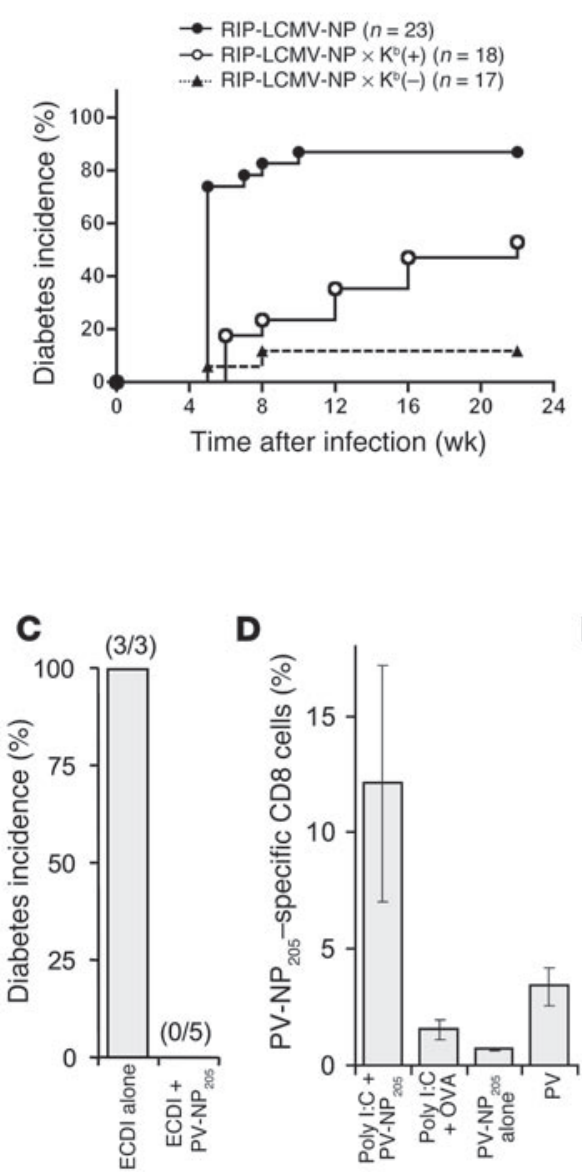

D

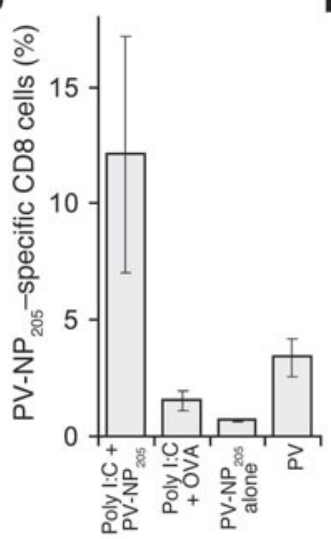

\section{B}

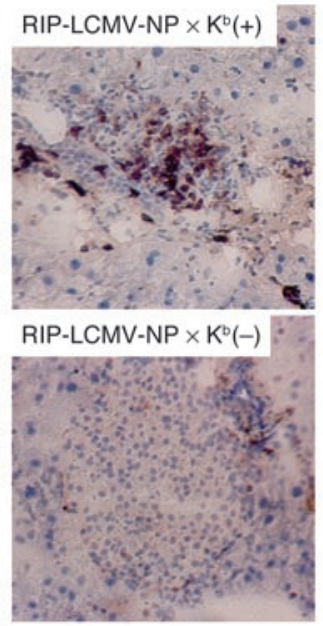

E

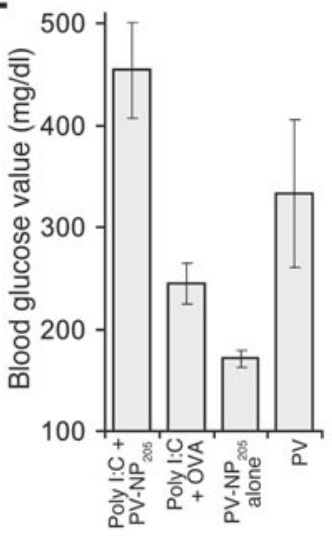

\section{Figure 4}

$\mathrm{H}-2 \mathrm{~K}^{\mathrm{b}}$-restricted, autoreactive, LCMV/PV-NP 205 -specific crossreactive CD8 T cells mediate the acceleration of diabetes. (A and B) RIP-LCMV-NP or RIP-LCMV-NP $\times \mathrm{K}^{\mathrm{b}}(-)$ mice were infected with LCMV or PV. After 4 weeks, the mice received a secondary infection of PV. (A) Blood glucose of RIP-LCMV-NP, RIP-LCMV$\mathrm{NP} \times \mathrm{K}^{\mathrm{b}}(-)$, and RIP-LCMV-NP $\times \mathrm{K}^{\mathrm{b}}(+)$ littermates was measured in weekly intervals. The diabetes onset curves (blood glucose values $>300 \mathrm{mg} / \mathrm{dl}$ ) for the groups [RIP-LCMV-NP $\times \mathrm{K}^{\mathrm{b}}(-)$ vs. RIP-LCMV-NP $\times \mathrm{K}^{\mathrm{b}}(+)$ ] are significantly different (log rank test; $P=0.0167)$. (B) Pancreas sections from 3-4 mice per group at week 3 after secondary infection with PV were stained for cellular infiltration of CD8 T cells. Sections of 1 representative RIP-LCMV$\mathrm{NP} \times \mathrm{K}^{\mathrm{b}}(-)$ and RIP-LCMV-NP $\times \mathrm{K}^{\mathrm{b}}(+)$ mouse are shown. Original magnification, $\times 20$. (C) Mice were tolerized to $\mathrm{PV}^{-N_{2}}{ }_{205}$ by injection of $2 \times 10^{7} \mathrm{ECDI}-\mathrm{PV}-\mathrm{NP}_{205}$-coupled autologous splenocytes $\left(\mathrm{ECDI}+\mathrm{NP}_{205}\right)$ or with $2 \times 10^{7}$ splenocytes treated with EDCI alone, 5 days before infection with $10^{5}$ PFU LCMV. After 4 weeks, mice were infected with PV. Diabetes incidence (blood glucose values > $300 \mathrm{mg} / \mathrm{dl}$ ) at week 4 after PV infection is displayed; numbers of mice analyzed per group are indicated in parentheses. (D and E) Groups of 3-4 mice were infected with LCMV. After 4 weeks, the mice received $100 \mu \mathrm{g}$ of $\mathrm{PV}-\mathrm{NP}_{205}$ peptide or an $\mathrm{H}-2 \mathrm{~K}^{\mathrm{b}}$-restricted control peptide (OVA; SIINFEKL). In addition, mice received three injections of poly $(\mathrm{I}: \mathrm{C})(7.5 \mu \mathrm{g} / \mathrm{g}$ body mass) at the time of peptide injection and then at days 2 and 4 thereafter. Controls received PV-NP 205 only or PV infection. (D) The frequency of blood LCMV/PV-NP ${ }_{205}$-specific cross-reactive CD8 $\mathrm{T}$ cells was assessed by flow cytometry using $\mathrm{H}-2 \mathrm{~K}^{\mathrm{b}}-\mathrm{PV}$ $\mathrm{NP}_{205}$ tetramers (day 7 after peptide injection). (E) Mean blood glucose values $( \pm$ SEM) measured at week 2 after peptide and/or poly $(\mathrm{I}: \mathrm{C})$ injection is displayed. the islets for subsequently arising PV-activated LCMV/PV-NP ${ }_{205}-$ specific cross-reactive CD8 $\mathrm{T}$ cells during the prediabetic phase. Indeed, in support of this argument, the reverse scenario in which $\mathrm{PV}$ was either given twice (Figure 3 ) or given as a first infection followed by infection with LCMV (data not shown), resulting in significant numbers of activated LCMV-PV-NP $205^{-}$but not LCMV$\mathrm{NP}_{396}$-specific CD8 $\mathrm{T}$ cells, respectively, did not result in accelerated diabetes. Earlier studies with the RIP-LCMV model suggest that transient infection of the pancreas with LCMV is likely to be important for the subsequent accumulation of autoreactive CD8 $T$ cells and $\beta$-cell damage. In agreement with this is the observation that LCMV-NP-specific lymphocyte lines that have been grown in vitro and transferred into RIP-LCMV-NP recipient mice were able to traffic to the target organ are unable to cause T1D unless the co-stimulator molecule B7.1 is coexpressed on $\beta$ cells, mimicking APC activation (38). Similarly, a recent study by Darabi et al. demonstrated that myelin oligodendrocyte glycoprotein-specific Th1 cells can elicit autoimmune pathology in the CNS only when the APCs in the target organ are activated by local inflammation caused by intracerebral deposition of toll-like receptor 9-activating $\mathrm{CpG}$ oligonucleotides (46).

We observed that the sequence in which the heterologous virus infections occurred affected the autoimmune outcome. This finding is important for understanding viral associations with autoimmune diseases, as not only the heterologous viral strains but also the order in which they infect the host appear to be important. These data contribute to a growing literature describing how the history of heterologous infections can skew $\mathrm{T}$ cell hierarchies, thereby altering antiviral immunity and subsequent immunopathologies $(27,47,48)$. A major implication is that the infectious history of a patient is of growing importance in defining agents that potentially can induce autoimmunity or push a preexisting autoimmune condition toward clinical disease. The primary triggering event, which might by itself be insufficient to cause clinically evident disease, would be followed by one or multiple secondary antigenic encounters that change the established $\mathrm{T}$ cell hierarchy. As a consequence, autoreactive $\mathrm{T}$ cells accumulate and become activated until they reach a critical mass and rapidly destroy enough cells or tissue, leading to clinical disease. Molecular mimicry could be involved in some or all of the above steps. Coupled with a certain genetic predisposition and possibly other unrelated inflammatory events of the target organ, molecular mimicry can thus be a highly adverse and disadvantageous event, even if no disease and only subclinical autoimmunity would result in otherwise healthy, nonpredisposed individuals. Future studies should investigate whether there is a significant time-wise association between critical infections and the development of clinical signs of autoimmune disease. Factors such as time and pattern of (heterologous) infections might account for the controversial association of T1D and rotavirus infections $(15,16)$. Additionally, because autoreactive lymphocytes frequently exhibit an activated phenotype in patients but 
not healthy controls, these cells should be evaluated selectively for their ability to cross-react with microbial ligand candidates. Ideally, appropriate searches will take conformational as well as sequential homologies into account. Possibly the prevention of certain infections found to present self-antigenic mimics or therapies aimed at skewing the $\mathrm{T}$ cell hierarchy away from a known autoimmune predisposition could in this way decrease the incidence of autoimmunity.

\section{Methods}

Transgenic mouse lines. The mouse line expressing the LCMV-NP (transgenic founder line RIP-NP 25-3) was generated in $\mathrm{H}-2^{\mathrm{b}} \mathrm{C} 57 \mathrm{BL} / 6-\mathrm{J}$ and $\mathrm{H}-2^{\mathrm{d}}$ $\mathrm{BALB} / \mathrm{c}$ mice using the RIP vector and cDNA clones for LCMV-NP and -GP. RIP-NP 25-3 mice expressed the transgene in both their pancreatic $\beta$ cells and their thymus but not in other tissues (29). Screening was done by PCR as described previously (29). $\mathrm{K}^{\mathrm{b}}(-)$ mice were obtained from B. Perarnau and F.A. Lemonnier (Departement SIDA-Retrovirus, Institut Pasteur, Paris, France) (49). RIP-LCMV-NP $\times \mathrm{K}^{\mathrm{b}}(-)$ mice were screened for $\mathrm{H}-2 \mathrm{~K}^{\mathrm{b}}$ deficiency by flow cytometry using phycoerythrin-conjugated anti-H- $2 \mathrm{~K}^{\mathrm{b}}$ (BD Biosciences - Pharmingen). The study was approved by the La Jolla Institute for Allergy and Immunology Animal Care Committee.

Viruses. LCMV-Arm clone 53b and LCMV-Arm-Var (33) were plaque-purified three times on Vero cells and stocks were prepared by a single passage on BHK-21 cells. Six- to ten-week-old mice were infected i.p. with a single dose of $10^{5} \mathrm{PFU}$ (29). PV was kindly provided by M.J. Buchmeier (The Scripps Research Institute, La Jolla, California, USA) (50) and was injected at a dose of $10^{5} \mathrm{PFU}$ per mouse.

Blood glucose values. Blood glucose was monitored at weekly intervals with the blood glucose monitoring system OneTouch Ultra (LifeScan Inc.). Diabetes was defined as a blood glucose values of more than $300 \mathrm{mg} / \mathrm{dl}$ (38).

Immunohistochemistry. Tissues were immersed in Tissue-Tek OCT (Bayer) and were quick-frozen on dry ice. Using cryomicrotome and sialin-coated Superfrost Plus slides (Fisher Scientific), 6- to 10- $\mu \mathrm{m}$ tissue sections were cut. Sections were then fixed with $90 \%$ ethanol at $-20^{\circ} \mathrm{C}$ and, after sections were washed in PBS, incubated with an avidin/biotin blocking kit (Vector Laboratories). Primary and biotinylated secondary antibodies (Vector Laboratories) were incubated for 60 minutes each, and color reaction was obtained by sequential incubation with avidinperoxidase conjugate (Vector Laboratories) and diaminobenzidinehydrogen peroxide. Primary antibodies used was rat anti-mouse CD8a (Ly2; BD Biosciences - Pharmingen).

CTL assays. Lytic activity of LCMV-specific CTLs was measured in a standard 5-hour in vitro ${ }^{51} \mathrm{Cr}$-release assay using syngeneic $\left(\mathrm{MC} 57, \mathrm{H}-2^{\mathrm{b}}\right)$ target cells infected with LCMV $(\mathrm{MOI}=0.1)$. Secondary CTL assays were performed after splenocyte restimulation for 5-6 days with irradiated, syngeneic, LCMV-infected peritoneal exudate cells (PECs) (51).

Flow cytometry. For intracellular stains, single-cell suspensions were restimulated for 5 hours with $1 \mu \mathrm{g} / \mathrm{ml}$ MHC class I-restricted viral peptides in the presence of brefeldin A. Cells were stained for surface expression of CD4 and CD8, fixed, permeabilized, and stained for intracellular IFN- $\gamma$ (antibodies were obtained from BD Biosciences - Pharmingen). Samples were acquired using a FACSCalibur (BD).

In vitro restimulation. For LCMV-specific responses, memory splenocytes were cultured for 6-10 days on LCMV-infected, irradiated APCs (peritoneal exudate macrophages from $\mathrm{H}-2^{\mathrm{b}}$ mice). After culture, viable cells were collected and cells were incubated for 5 hours with peptide in the presence of brefeldin A before being stained for intracellular IFN- $\gamma(38)$.

Precursor frequency analysis. For precursor frequency analysis, spleen cells were harvested on day 60 after primary LCMV infection. These cells were serially diluted and were cultivated in 96-well flat-bottomed plates in the presence of $\mathrm{T}$ cell growth factor and syngeneic, irradiated, LCMVinfected $\left(10^{3} \mathrm{PFU} / \mathrm{ml}\right)$ spleen cells $\left(10^{5}\right.$ cells/well). After 5-9 days, each well was assayed for CTL lysis (described above) on target cells that were left uninfected or were infected with LCMV. The fraction of positive cultures (lysis > 11\%) was determined for each dilution (38).

In situ tetramer stains. Briefly, fresh frozen sections $6 \mu \mathrm{m}$ in thickness were cut from the organs of interest and were stained with a phycoerythrin-labeled MHC class I tetramer $(1.0 \mu \mathrm{g} / \mathrm{ml})$ with $2 \%$ normal goat serum (NGS) and rat anti-CD $8 \alpha(0.5 \mu \mathrm{g} / \mathrm{ml})$. Staining with tetramer containing an irrelevant peptide was used as a negative control. After an overnight incubation at $4^{\circ} \mathrm{C}$, sections were washed in PBS and then fixed for 30 minutes at room temperature with PBS-buffered $2 \%$ formaldehyde. Sections were washed again in PBS and were incubated for 3 hours at $4^{\circ} \mathrm{C}$ with polyclonal rabbit anti-phycoerythrin diluted 1:2,500 in PBS with $2 \%$ NGS. Afterward, sections were washed and were incubated for 3 hours at $4{ }^{\circ} \mathrm{C}$ with rhodamine red $\mathrm{X}$-conjugated donkey anti-rabbit and FITC-conjugated goat anti-rat diluted 1:1,000 in PBS with $2 \%$ NGS. Rhodamine red X-positive and FITC-positive T lymphocytes were analyzed with a confocal microscope (40).

EDCI tolerization. Splenocytes were isolated from C57BL/ 6 mice and were incubated for 1 hour on ice at a concentration of $3.2 \times 10^{8}$ cells $/ \mathrm{ml}$ with 1 $\mathrm{mg} \mathrm{NP} 205$ peptide in presence of $30 \mathrm{mg} / \mathrm{ml}$ EDCI (Sigma-Aldrich) $(43,44)$. Cross-linked splenocytes were washed and $2 \times 10^{7}$ cells were injected retroorbitally into recipient mice. Primary infection with $10^{5}$ PFU LCMV-Arm was at day 5 after adoptive transfer. At week 4 after LCMV infection, mice received a secondary infection with $10^{5} \mathrm{PFU} \mathrm{PV}$.

Poly(I:C) treatment. Mice were infected with $10^{5} \mathrm{PFU}$ LCMV. At week 4 after infection, mice received a single dose (i.p.) of $100 \mu \mathrm{g} \mathrm{NP} 205$ peptide or the $\mathrm{H}-2 \mathrm{~K}^{\mathrm{b}}$-binding control OVA peptide (SIINFEKL). At the same time, mice received $7.5 \mu \mathrm{g} / \mathrm{g}$ body mass of the synthetic double-stranded viral RNA mimic poly(I:C).

\section{Acknowledgments}

This is Publication 625 of the Department of Developmental Immunology, La Jolla Institute for Allergy and Immunology. M.G. von Herrath was supported by NIH grants AI44451, DK51091, and AI51973. U. Christen was a recipient of a Juvenile Diabetes Research Foundation fellowship and a career development award by the American Liver Foundation. K.H. Edelmann was supported by NIH training grant NS041219. M.B.A. Oldstone was supported by NIH grants DK58541 and AI09484. We thank Michael J. Buchmeier (The Scripps Research Institute, La Jolla, California, USA) for providing us with PV. We are grateful to J. Lindsey Whitton (The Scripps Research Institute, La Jolla, California, USA) and Howard M. Grey (La Jolla Institute for Allergy and Immunology, San Diego, California, USA) for critically reviewing our manuscript, and we thank Diana Frye for assistance with the manuscript.

Received for publication June 28, 2004, and accepted in revised form September 10, 2004.

Address correspondence to: Matthias G. von Herrath, Department of Developmental Immunology, La Jolla Institute for Allergy and Immunology, 10355 Science Center Drive, San Diego, California 92121, USA. Phone: (858) 558-3671; Fax: (858) 558-3579; E-mail: matthias@liai.org.

Urs Christen and Kurt H. Edelmann contributed equally to this work. 
1. Sibley, W.A., Bamford, C.R., and Clark, K. 1985 Clinical viral infections and multiple sclerosis. Lancet. 1:1313-1315.

2. Gamble, D.R., Moffatt, A., and Marks, V. 1979 Serum immunoreactive trypsin concentrations in infectious and non-infectious illnesses and in juvenile diabetes. J. Clin. Pathol. 32:897-901.

3. Menser, M.A., Forrest, J.M., and Bransby, R.D. 1978. Rubella infection and diabetes mellitus. Lancet. 1:57-60.

4. Notkins, A.L., and Yoon, J.-W. 1984. Virus-induced diabetes mellitus. In Concepts in Viral Pathogenesis. A.L. Notkins and M.B.A. Oldstone, editors. Springer-Verlag. New York, New York, USA. 241-247.

5. Yoon, J.-W. 1990. The role of viruses and environmental factors in the induction of diabetes. Curr Top. Microbiol. Immunol. 164:95-123.

6. Kurtzke, J.F., and Hyllested, K. 1979. Multiple sclerosis in the Faroe Islands: I. Clinical and epidemiological features. Ann. Neurol. 5:6-21.

7. Kurtzke, J.F. 1993. Epidemiologic evidence for multiple sclerosis as an infection. Clin. Microbiol. Rev. 6:382-427.

8. Cermelli, C., et al. 2003. High frequency of human herpesvirus 6 DNA in multiple sclerosis plaques isolated by laser microdissection. J. Infect. Dis. 187:1377-1387.

9. Tejada-Simon, M.V., Zang, Y.C., Hong, J., Rivera, V.M., and Zhang, J.Z. 2003. Cross-reactivity with myelin basic protein and human herpesvirus- 6 in multiple sclerosis. Ann. Neurol. 53:189-197.

10. Oldstone, M.B. 1998. Molecular mimicry and immune-mediated diseases. FASEB J. 12:1255-1265.

11. Oldstone, M.B.A. 1987. Molecular mimicry and autoimmune disease. Cell. 50:819-820

12. Srinivasappa, J., et al. 1986. Molecular mimicry: Frequency of reactivity of monoclonal antiviral antibodies with normal tissues. J. Virol. 1986:397-401.

13. Fujinami, R.S., and Oldstone, M.B. 1985. Amino acid homology between the encephalitogenic site of myelin basic protein and virus: mechanism for autoimmunity. Science. 230:1043-1045.

14. Wucherpfennig, K.W., and Strominger, J.L. 1995. Molecular mimicry in T cell-mediated autoimmunity: viral peptides activate human $\mathrm{T}$ cell clones specific for myelin basic protein. Cell. 80:695-705.

15. Honeyman, M.C., et al. 2000. Association between rotavirus infection and pancreatic islet autoimmunity in children at risk of developing type 1 diabetes. Diabetes. 49:1319-1324.

16. Blomqvist, M., et al. 2002. Rotavirus infections and development of diabetes-associated autoantibodies during the first 2 years of life. Clin. Exp. Immunol. 128:511-515

17. Oldstone, M.B.A. 1989. Molecular mimicry as a mechanism for the cause and as a probe uncovering etiologic agent(s) of autoimmune disease. Curr Top. Microbiol. Immunol. 145:127-136.

18. Cantor, H. 2000. T cell receptor crossreactivity and autoimmune disease. Adv. Immunol. 75:209-233.

19. Miller, S.D., Katz-Levy, Y., Neville, K.L., and Vanderlugt, C.L. 2001. Virus-induced autoimmunity: epitope spreading to myelin autoepitopes in Theiler's virus infection of the central nervous system. Adv. Virus Res. 56:199-217.

20. Olson, J.K., Croxford, J.L., Calenoff, M.A., Dal Canto, M.C., and Miller, S.D. 2001. A virusinduced molecular mimicry model of multiple sclerosis. J. Clin. Invest. 108:311-318. doi:10.1172/
JCI200113032.

21. Miller, S.D., et al. 1997. Persistent infection with Theiler's virus leads to CNS autoimmunity via epitope spreading. Nat. Med. 3:1133-1136.

22. Tian, J., Lehmann, P.V., and Kaufman, D.L. 1994 $\mathrm{T}$ cell cross-reactivity between coxsackievirus and glutamate decarboxylase is associated with a murine diabetes susceptibility allele. J. Exp. Med. 180:1979-1984.

23. Horwitz, M.S., et al. 1998. Diabetes induced by Coxsackie virus: initiation by bystander damage and not molecular mimicry. Nat. Med. 4:781-785.

24. Serreze, D.V., Ottendorfer, E.W., Ellis, T.M., Gauntt, C.J., and Atkinson, M.A. 2000. Acceleration of type 1 diabetes by a coxsackievirus infection requires a preexisting critical mass of autoreactive T cells in pancreatic islets. Diabetes. 49:708-711.

25. Panoutsakopoulou, V., et al. 2001. Analysis of the relationship between viral infection and autoimmune disease. Immunity. 15:137-147.

26. Deshpande, S., et al. 2001. Bystander activation involving $\mathrm{T}$ lymphocytes in herpetic stromal keratitis. J. Immunol. 167:2902-2910.

27. Brehm, M.A., et al. 2002. T cell immunodominance and maintenance of memory regulated by unexpectedly cross-reactive pathogens. Nat. Immunol. 3:627-634

28. von Herrath, M.G., Fujinami, R.S., and Whitton, J.L. 2003. Microorganisms and autoimmunity: making the barren field fertile. Nat. Rev. Microbiol. 1:151-157.

29. von Herrath, M.G., Dockter, J., and Oldstone, M.B. 1994. How virus induces a rapid or slow onset insulin-dependent diabetes mellitus in a transgenic model. Immunity. 1:231-242.

30. Oldstone, M.B., Nerenberg, M., Southern, P., Price, J., and Lewicki, H. 1991. Virus infection triggers insulin-dependent diabetes mellitus in a transgenic model: Role of anti-self (virus) immune response. Cell. 65:319-331.

31. Seewaldt, S., et al. 2000. Virus-induced autoimune diabetes: Most b-cells die through inflammatory cytokines and not perforin from autoreactive (antiviral) CTL. Diabetes. 49:1801-1809.

32. Sevilla, N., et al. 2000. Virus-induced diabetes in a transgenic model: role of cross-reacting viruses and quantitation of effector $T$ cells needed to cause disease. J. Virol. 74:3284-3292.

33. Lewicki, H., et al. 1995. CTL escape viral variants. I. Generation and molecular characterization. Virology. 210:29-40.

34. Gairin, J.E., Mazarguil, H., Hudrisier, D., and Oldstone, M.B. 1995. Optimal lymphocytic choriomeningitis virus sequences restricted by $\mathrm{H}-2 \mathrm{Db}$ major histocompatibility complex class I molecules and presented to cytotoxic T lymphocytes. J. Virol. 69:2297-2305.

35. Whitton, J.L., et al. 1989. Molecular analyses of a five-amino-acid cytotoxic T-lymphocyte (CTL) epitope: an immunodominant region which induces nonreciprocal CTL cross-reactivity.J. Virol. 63:4303-4310.

36. von Herrath, M.G., and Holz, A. 1997. Pathological changes in the islet milieu precede infiltration of islets and destruction of $\beta$-cells by autoreactive lymphocytes in a transgenic model of virus-induced IDDM. J. Autoimmun. 10:231-238.

37. Christen, U., McGavern, D.B., Luster, A.D., von Herrath, M.G., and Oldstone, M.B. 2003. Among
CXCR3 chemokines, IFN-gamma-inducible protein of $10 \mathrm{kDa}$ (CXC chemokine ligand (CXCL) 10) but not monokine induced by IFN-gamma (CXCL9) imprints a pattern for the subsequent development of autoimmune disease. J. Immunol. 171:6838-6845

38. von Herrath, M.G., Guerder, S., Lewicki, H., Flavell, R.A., and Oldstone, M.B. 1995. Coexpression of B7-1 and viral ("self") transgenes in pancreatic beta cells can break peripheral ignorance and lead to spontaneous autoimmune diabetes. Immunity. 3:727-738

39. Christen, U., et al. 2004. Cure of prediabetic mice by viral infections involves lymphocyte recruitment along an IP-10 gradient. J. Clin. Invest. 113:74-84. doi:10.1172/JCI200417005.

40. McGavern, D.B., Christen, U., and Oldstone, M.B. 2002. Molecular anatomy of antigen-specific CD8 ${ }^{+}$ $\mathrm{T}$ cell engagement and synapse formation in vivo. Nat. Immunol. 3:918-925.

41. Puglielli, M.T., et al. 2001. In vivo selection of a lymphocytic choriomeningitis virus variant that affects recognition of the GP33-43 epitope by H2Db but not H-2Kb. J. Virol. 75:5099-5107.

42. von Herrath, M.G., Wolfe, T., Mohrle, U., Coon, B., and Hughes, A. 2001. Protection from type 1 diabetes in the face of high levels of activated autoaggressive lymphocytes in a viral transgenic mouse model crossed to the SV129 strain. Diabetes. 50:2700-2708.

43. Miller, S.D., Wetzig, R.P., and Claman, H.N. 1979. The induction of cell-mediated immunity and tolerance with protein antigens coupled to syngeneic lymphoid cells. J. Exp. Med. 149:758-773.

44. Vandenbark, A.A., Celnik, B., Vainiene, M., Miller, S.D., and Offner, H. 1995. Myelin antigen-coupled splenocytes suppress experimental autoimmune encephalomyelitis in Lewis rats through a partially reversible anergy mechanism. J. Immunol. 155:5861-5867.

45. Slifka, M.K., et al. 2003. Preferential escape of subdominant CD8+ T cells during negative selection results in an altered antiviral $\mathrm{T}$ cell hierarchy. J. Immunol. 170:1231-1239.

46. Darabi, K., et al. 2004. The third signal in T cell-mediated autoimmune disease? J. Immunol. 173:92-99.

47. Welsh, R.M., and Selin, L.K. 2002. No one is naive: the significance of heterologous $\mathrm{T}$ cell immunity. Nat. Rev. Immunol. 2:417-426.

48. Chen, H.D., Fraire, A.E., Joris, I., Welsh, R.M., and Selin, L.K. 2003. Specific history of heterologous virus infections determines anti-viral immunity and immunopathology in the lung. Am. J. Pathol. 163:1341-1355.

49. Perarnau, B., et al. 1999. Single H2Kb, H2Db and double $\mathrm{H} 2 \mathrm{KbDb}$ knockout mice: peripheral CD8+ T cell repertoire and anti-lymphocytic choriomeningitis virus cytolytic responses. Eur. J. Immunol. 29:1243-1252.

50. Buchmeier, M.J., Lewicki, H.A., Tomori, O., and Oldstone, M.B. 1981. Monoclonal antibodies to lymphocytic choriomeningitis and pichinde viruses: generation, characterization, and cross-reactivity with other arenaviruses. Virology. 113:73-85.

51. von Herrath, M.G., Dockter, J., Nerenberg, M., Gairin, J.E., and Oldstone, M.B. 1994. Thymic selection and adaptability of cytotoxic T lymphocyte responses in transgenic mice expressing a viral protein in the thymus. J. Exp. Med. 180:1901-1910. 